\title{
HOMERO EN LA FORMACIÓN RETÓRICO-ESCOLAR GRIEGA: ETOPEYAS CON TEMA DEL CICLO TROYANO*
}

\author{
JESÚs UREÑA BRACERO \\ Universidad de Extremadura
}

This paper is a broad study of ethopoeia with themes from the Troyan cycle. It is an attempt to interrelate data from rhetorical rules in school exercise manuals, and from the extant practical examplesith the importance of the Homeric model (texts, scholia, commentaries).

\section{Introducción}

Con este trabajo pretendemos aclarar algunos aspectos del empleo de Homero en la formación retórico-escolar antigua desde el s. III d. C. en adelante, aunque las conclusiones pudieran retrotraerse al menos hasta el s. I d. C. Para ello hemos abordado el estudio de la etopeya (???p???a), un ejerci-

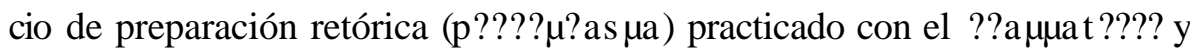
con el ??t??, y consistente en hacer hablar a dioses, héroes o cualquier otro personaje de acuerdo con su carácter, edad y condición en una situación determinada ${ }^{1}$. En un artículo reciente el profesor J. A. Fernández Delgado ha

* Este trabajo se encuadra dentro del Proyecto Subvencionado por la DGES (PB971311) y por la Consejería de Educación y Cultura de la Junta de Castilla y León (B.O.C. y L. de 26 de Enero de 1999). Deseo agradecer sus sugerencias y correcciones a D. José Antonio Fernández Delgado, D. Pedro Juan Galán Sánchez, D. Juan Carlos Iglesias Zoido y D. Manuel Sanz Morales.

$1 \quad$ Cf. Theon, 2.115 Sp.; Hermog., 20 R.; y Aphth., 2.44 Sp. Sobre los ejercicios de preparación retórica en general, véase G. Reichel, Quaestiones Progymnasmaticae, Leipzig, 1909; O. Schissel, «Die rhetorische Progymnasmatik der Byzantiner», Byzantinisch-Neugriechische Jahrbücher XI, 1934-5, pp. 1-10; D. L. Clark, Rhetoric in Greco-Roman Education, N. York, 
catalogado y estudiado las etopeyas hexamétricas conservadas en papiro y otros materiales ${ }^{2}$. En su mayor parte, y al igual que otras muchas etopeyas transmitidas por vía indirecta, presentan temática mitológica y del ciclo troya$\mathrm{no}^{3}$. Pues bien, el abundante material existente del ciclo troyano, y particularmente homérico, disponible tanto en prosa como en verso, nos ha parecido que merecía un tratamiento específico, a fin de explicar la actitud adoptada por los autores en su confección. Para ello ha sido necesario llevar a cabo un estudio de los textos que, además de examinar la temática y la preceptiva retóricas, abordase el comentario de las posibles fuentes y su modo de empleo. Pensábamos que de tal estudio podrían extraerse conclusiones que aclararan aspectos concretos de la elaboración del ejercicio en la escuela y fuera de ella, sobre todo los que atañen al empleo del material homérico.

Por otro lado, como se desprende de la lectura de los escolios y comentarios homéricos, determinados pasajes homéricos llamaron la atención de los comentaristas antiguos por su eficacia caracterizadora. Naturalmente dichos pasajes influyeron sobre los ejercicios prácticos, pero también sobre la propia

1957, pp. 157-212; T. Viljamaa, Studies in Greek Encomiastic Poetry of the Early Byzantine Period, Helsinki, 1968, pp. 13-24; S. F. Bonner, La educación en la Roma antigua. Desde Catón el viejo a Plinio el Joven, Barcelona, 1984, pp. 328-60; G. A. Kennedy, Greek Rhetoric under Christian Emperors, Princeton, 1983, pp. 54-70; B. Schouler, La tradition hellenique chez Libanios, París, 1984, vol. 1, pp. 27-138; Mª D. Reche Martínez, Teón. Hermógenes. Aftonio. Ejercicios de retórica, Introducción, traducción y notas de ..., Madrid, 1991, pp. 746; y M. Patillon, Aelius Théon. Progymnasmata, París, 1997, pp. VII-CXIV; una historia de los ejercicios puede leerse en M. Kraus, «Exercitatio», en Historisches Wörterbuch der Rhetorik, G. Ueding (ed.), vol. 3, 1996, pp. 71-123. Sobre la etopeya, véase, además, H. M. Hagen, ????p???a . Zur Geschichte eines rhetorischen Begriffs, Diss. Nürnberg, 1966, p. 56 y ss.; y J. L. Fournet, «Une éthopée de Caïn dans le Codex des Visions de la Fondation Bodmer», ZPE XCII, 1992, pp. 253-66. Para la historia de la etopeya en época bizantina, véase Schissel (1934-5), pp. 7-10; H. Hunger, Die hochsprachliche profane Literatur der Byzantiner, vol. 1, Múnich, 1978, pp. 108-16; y A. Kazhdan e I. Sevcenko, «Ethopoiia», en The Oxford Dictionary of Byzantium, Oxford, 1991, vol. 2, pp. 734-5.

2 J. A. Fernández Delgado, «Hexametrische-Ethopoiíai auf Papyrus und anderen Materialien», Proceedings of the XX International Congress of Papyrologists collected by A. Büllow-Jacobsen, Copenhague, 1994, pp. 299-305.

3 Sobre la presencia de esta temática en los papiros que contienen ejercicios retóricos, cf. T. Morgan, Literate education in the Hellenistic and Roman worlds, Cambridge, 1998, p. 219 y ss. 
preceptiva teórica ${ }^{4}$ de la etopeya, un ejercicio cuyo principal modelo era Homero. A lo largo de los siglos el texto homérico, sus escolios y comentarios, la preceptiva de la etopeya (y los modelos en ella propuestos) y los ejercicios prácticos mantuvieron una relación de interdependencia e influencia mutua, cuyo estudio resulta de gran importancia, tanto para explicar determinadas características de las composiciones prácticas y la naturaleza de algunos comentarios homéricos como para entender la evolución de la preceptiva retórica de la etopeya. Se trata de un método de acercamiento a los ejercicios de preparación retórica, a nuestro juicio, poco aprovechado hasta ahora ${ }^{5}$.

\section{Presencia de Homero en la preceptiva de la etopeya.}

Con gran acierto dijo Platón que Homero había "educado a la Hélade" (R. 606e). La epopeya homérica ha sido considerada recientemente por Havelock una "Enciclopedia tribal", en la que los griegos encontraban modelos de vida y conducta, así como recomendaciones para todos los aspectos de la vida diaria ${ }^{6}$. Heráclito, autor posiblemente del s. I d. C., dice en sus Alegorías de Homero (1.5-7) que el prolongado contacto con Homero durante toda la vida no provoca hastío alguno sino todo lo contrario. Son muchos más

\footnotetext{
4 La información teórica en lengua griega sobre la etopeya procede principalmente de los manuales de ejercicios de preparación retórica obra de Teón (s. I-II d. C.), Hermógenes (II d. C.), Aftonio (IV d. C.) y Nicolás de Mira (V d. C.), sus escolios y los comentarios a los ejercicios de Aftonio de Juan de Sardes (VIII-IX d. C.) y Doxopatros (XI d. C.). Los textos de los rétores y escoliastas son citados según las siguientes ediciones: Rhetores Graeci, vols. 2 y 3, L. Spengel, Leipzig. 1854 y 1856 = Sp.; Ioannis Sardiani commentarium in Aphthoniis Progymnasmata, H. Rabe, Leipzig, 1928 = R.; Rhetores Graeci, vol. 1 y 2, C. Waltz, Stuttgart, 1832-6 = W.; Rhetores Latini Minores, C. Halm, ed., Frankfurt, 1964, reimpresión de Leipzig, 1863 = H.; Hermogenis Opera, H. Rabe, Stuttgart, 1969, reimpresión de 1913 = R.

5 Un interesante trabajo en esta línea es el llevado a cabo por $\mathrm{M}^{\mathrm{a}} \mathrm{V}$. Pérez Custodio, «La expresión del ethos y el pathos en las etopeyas escolares del Renacimiento», en Humanismo y Pervivencia del Mundo Clásico. II. Homenaje al profesor Luis Gil, Cádiz, 1997, vol. 2, pp. 795-806, si bien recoge sobre todo datos de la tradición occidental (latina) del ejercicio durante el Renacimiento. Según su autora, los hechos que facilitaron la evolución sufrida por la etopeya en favor de la presencia de lo emotivo en cualquiera de los tipos fueron los siguientes: la alteración de la definición etimológica antigua del ejercicio, la abundancia de comentarios que recomendaban lo patético, las lecturas complementarias sugeridas y los ejercicios prácticos desarrollados con predominio de la expresión del pathos (p. 798). Tal explicación es, asimismo, perfectamente válida para la etopeya en época bizantina.
}

6 E. A. Havelock, Prefacio a Platón, Madrid, 1994, p. 75. 
los testimonios acerca de la importancia de Homero en la educación ${ }^{7}$, pero bastaría con un breve recorrido por los ejercicios presentes en los textos escolares para atestiguarlo ${ }^{8}$. En efecto, la presencia de Homero es abrumadora desde la copia y dictado, aprendizaje de memoria, separación de palabras, ejercicios de contenido gramatical, glosarios y léxicos, cuestionarios, resúmenes, paráfrasis, narraciones y ejercicios sobre prosodia, etopeyas, etc. ${ }^{9} \mathrm{Y}$ es que, como recuerda Viljamaa ${ }^{10}$, Homero fue la norma para la poesía y para toda forma de elocuencia (cf. Quint., Inst. X 1,27 y ss.); en él vio Hermógenes al mejor poeta, rétor y logógrafo (390 R.) y fue considerado por Pseudo-Dionisio el maestro de los tres tipos de oratoria (D.H., Imit. 6.2, p. 204 U.-R. $)^{11}$ : en pocas palabras, puede decirse que Homero fue el medio y

7 Sobre la importancia de la épica homérica en la educación, véase H.-I. Marrou, Historia de la educación en la antigüedad, Madrid, 1985; W. J. Verdenius, Homer, the Educator of the Greeks, Amsterdam (1970); y K. Robb, Literacy and Paideia in Ancient Greece, N. York, 1994, pp. 159-82. Visiones generales sobre los críticos de Homero pueden leerse en N. Richardson, «Homer and his ancient critics», en The Iliad: A Commentary. Volume VI: books 21-24, Cambridge, 1993, pp. 25-49; R. Lamberton, «Homer in Antiquity», en I. Morris y B. Powell, A New Companion to Homer, Leiden-N. York-Colonia, 1997, pp. 33-54. Para el conocimiento y tratamiento de Homero en época bizantina, véase R. Browning, «Homer in Byzantium», Viator VI, 1975, pp. 15-33 y «The Byzantines and Homer», en R. Lamberton y J. J. Keaney, Homer's Ancient Readers, Princeton, 1992, pp. 134-48.

8 Sobre textos escolares, véanse las selecciones y estudios de E. Ziebarth, Aus der antiken Schule, Bonn, 1913; G. Nachtergaell, Dans les classes d'Egypte d'après les papyrus scolaires grecs, Bruselas, 1980; H. Harrauer y J. Sijpesteijn, Neue Texte aus dem antiken Unterricht, Viena, 1985; y R. Cribiore, Writing, Teachers and Students in Graeco-Roman Egypt, Atlanta, 1996; y los catálogos de P. Collart, «Les papyrus scolaires», en Mélanges offerts à A.-M. Desrousseaux, París, 1937, pp. 69-80; G. Zalateo, «Papiri scolastici», Aegyptus XLI, 1961, pp. 160-235; R. A. Pack, The Greek and Latin Literary Texts from Greco-Roman Egypt, Ann Arbor, 1965², n 2642-751; J. Debut, «Les Documents scolaires», ZPE LXIV, 1986, pp. 246-78; y R. Cribiore, Writing, Teachers and Students in Graeco-Roman Egypt, pp. 175-284.

9 cf. J. Debut, «L'apprentissage du grec en Égypte ou le changement dans la continuité», StudClas 25, 1987, pp. 7-21; sobre el empleo de Homero en las distintas etapas de la formación (copia, dictado, composición, caligrafía y “educación superior”), véase M. H. Ibrahim, «The study of Homer in Graeco-Roman education», Athena 76, 1976-7, pp. 187-95.

10 Viljamaa, Studies in Greek Encomiastic Poetry of the Early Byzantine Period, p. 33.

11 Sobre Homero como base y padre de la retórica, léase, por ejemplo, Ps.-Plutarco, Sobre la vida y poesía de Homero, cap. 161-74; en L. Radermacher, Artium scriptores: Reste der voraristotelischen Rhetorik, Viena, 1951, A 2-4, pp. 3-10, aparece recogido un gran número de 
el fin de la formación en Grecia (D. Chr., Or. 18.8).

Como era de esperar, la presencia de Homero en los manuales de ejercicios de preparación retórica fue continua ${ }^{12}$. Así, Teón recuerda que Homero fue desde antiguo objeto de paráfrasis $(2.62 \mathrm{Sp}$.) y son numerosos los ejemplos homéricos de anécdotas, sentencias de todo tipo, relatos, comparaciones, descripciones y, cómo no, también de etopeyas.

Según Teón, los mejores ejemplos de etopeya se encuentran en Homero, Platón y los diálogos socráticos, y las comedias de Menandro (2.68 Sp.). Homero, en concreto - según Teón - siempre pone en boca de los personajes las palabras adecuadas (2.60 Sp.). Ello hace que en los manuales de ejercicios de preparación retórica los personajes homéricos sean los protagonistas de la mayor parte de las etopeyas. Así, el nombre de Aquiles es citado por Hermógenes (20 R.) a la hora de explicar lo que es una etopeya "de personaje determinado", es decir, aquel cuyo nombre es conocido. Además, la obra homérica contiene espléndidos ejemplos de todo tipo de etopeyas. Las palabras de Aquiles dichas ante el cuerpo de Patroclo (Il. XVIII 324-42) y en su reincorporación al combate son citadas como ejemplo de "etopeya mixta", etopeya con ???? y p???? (Hermog., 21 R.). De "etopeyas patéticas", es decir, composiciones en las que el personaje expresa páqoj (dolor, pena, rabia, etc.), son calificadas las intervenciones de Andrómaca en Il. XXIV 724-45 ante el cadáver de Héctor (Hermog., 21 R.), la de Briseida en Il. XIX 287-300 ante el de Patroclo (Sardianus, 205 R.) y las palabras dichas por Andrómaca al caer Héctor (Nicol., 3.489 Sp.), cuyo modelo sería Il. XXII 477-514. Emporio nos recuerda como ejemplo de "etopeya patética"

textos que muestran a los héroes homéricos como modelos de habilidades retóricas y presentan a Homero como el inventor de todas las ramas y aspectos de la retórica. Sobre ello, véase, además, F. Cairns, Generic Composition in Greek and Roman Poetry, Edimburgo, 1972, p. 34 y ss., y el esclarecedor capítulo «Homero, promotor de la poética» de A. López Eire, Orígenes de la poética, Salamanca, 1980, pp. 119 y ss.

12 Cf. Viljamaa, Studies in Greek Encomiastic Poetry of the Early Byzantine Period, p. 23. Sobre el conocimiento de Homero en el Egipto greco-romano, cf. J. A. Davison, «The Study of Homer in Graeco-Roman Egypt», Mitteilungen aus der Papyrussammlung der Österreichischen Nationalbibliothek, n. s. 5, 1956, pp. 51-8; sobre la presencia de Homero en los ejercicios de escuela, cf. R. Cribiore, «Literary School Exercises», ZPE 116, 1997, pp. 57-8, y «Gli esercizi scolastici dell'Egitto greco-romano: cultura letteraria e cultura populare nella scuola», en La letteratura di consumo nel mondo greco-latina, O. Pecere y A. Stramaglia, eds., Univ. di Cassino, 1996, pp. 511-2; véase también Morgan, Literate education..., pp. 105-15. 
las palabras de Aquiles cuando en $I l$. XXI 273-83 se ve acosado por el río Escamandro (562 H.). Los consejos de Néstor a Antíloco en Il. XXIII 30648 corresponden a lo que algunos rétores llaman "etopeya protréptica" o de tipo "práctico" (Sardianus, 199 R.), etopeya en la que alguien aconseja a otro cómo hacer algo, y cuya naturaleza y denominación recuerdan alguno de los modos de acción que, según Teón, pueden adoptarse en la confección de la etopeya (cf. $2.116 \mathrm{Sp}$.); al mismo tipo pertenecería también $O d$. XVI 268307, donde Odiseo dice a Telémaco cómo dar muerte a los pretendientes (Doxopatros, 2.501 W.). Las escenas de Odisea en que Odiseo es reconocido por Telémaco y Penélope (Od. XVI 194 y ss. y XXIII 209 y ss.) son citadas como ejemplos de etopeyas "de dos personajes" (Sardianus, 211 R.). Y tampoco faltan "idolopeyas" o etopeyas en las que habla un muerto, como cuando en $O d$. XI y $O d$. XXIV 15 y ss. Agamenón, Ayante y Aquiles hablan después de muertos (Sardianus, 203 R.); y cuando en Il. XXIII 69-92 Patroclo habla en sueños a Aquiles (Sardianus, 203 R.). Un claro ejemplo, en fin, de "prosopopeya" o etopeya en la que habla un ser irracional es Il. XIX 40817, donde Janto, el caballo de Aquiles, cobra voz por unos momentos (Sardianus, 204 R.).

En ocasiones la materia homérica sugiere nuevos discursos no desarrollados en Ilíada y Odisea. Así, aunque Aquiles habla a Patroclo poco antes de armarlo (Il. XVI 126-9), la etopeya de ese mismo título a la que se refieren los rétores sería en parte una creación propia del alumno (Sardianus, 206 R.). Algo similar podría decirse de la etopeya "lo que diría Odiseo a Circe al ver a sus compañeros metamorfoseados" (Sardianus, $211 \mathrm{R}$.), pues si bien en Od. X 388-99 Circe devuelve a su forma a los hombres de Odiseo en su presencia, nada dice Odiseo en ese momento. Por su parte, las palabras de Patroclo al ver cómo muere Héctor (Sardianus, 202 R.) constituirían una magnífica "idolopeya". Y ese mismo tono de venganza delatarían, seguramente, las palabras de Palamedes al ver a Odiseo vagar por todas partes (Sardianus, 202 R.).

Encontramos también en los rétores algunos títulos de etopeya de temática posthomérica. De tipo "ético" o de carácter serían las palabras de Agamenón al tomar Ilio (Nicol., 3.489 Sp.), y las de Menelao en ese mismo momento al no encontrar a Helena (Sardianus, 211 R.); y de tipo "patético" o emotivo, las palabras de Príamo y Hécuba ante la caída de Ilio (Sardianus, 
205 R., y Doxopatros, 2.498 W.), y las de Peleo al saber la muerte de Aquiles (Nicol., 3.490 Sp.). Por su parte, dentro del apartado de etopeyas con temática prehomérica incluimos la etopeya titulada «¿Qué palabras dirigiría Aquiles a Deidamía cuando él iba a partir hacia la guerra?» (Hermog., 20 R.).

Homero es ya alabado como hábil caracterizador por Aristóteles cuando en su Poética (1460a 11) afirma que todo personaje homérico, sea hombre, mujer o cualquier otra cosa, tiene "carácter": e?s??e? ? ?d?a ? ???a??a ? ???? t? ?a? ??d??' ????, ???' ????ta ? ??' ${ }^{13}$. Dicha opinión fue transmitida a lo largo de los siglos por rétores y por quienes ejercieron la crítica literaria ${ }^{14}$. Ahora bien, aunque es cierto que Homero compuso un gran número de intervenciones en estilo directo (casi el 50\% del total de su obra), resulta, sin embargo, algo más difícil encontrar en Homero caracterizaciones de personajes ${ }^{15}$. En la actualidad los estudiosos no se ponen de acuerdo al respecto. En cambio, entre los críticos antiguos esa opinión es unánime, pues consideran que los personajes homéricos dicen en todo momento lo que tienen que decir y como tienen que decirlo. Entre otros muchos pasajes, sirvieron para otorgarle tal fama los siguientes: la despedida de Héctor y Andrómaca, la embajada ante Aquiles con la presencia de Fénix, Odiseo y Ayante en el canto IX de Ilíada, los lamentos finales ante el cadáver de Héctor puestos en boca de Andrómaca, Hécuba y Helena, y el diálogo entablado por Odiseo con sus compañeros muertos en el canto XI de Odisea. Por tanto, no es extraño que las situaciones de Ilíada y Odisea hayan servido de punto de partida para las etopeyas; especialmente las de Ilíada, en general más empleadas que las de Odisea por los antiguos.

13 También la mención que hace Teón de los diálogos socráticos procede de Aristóteles, en concreto del pasaje de la Retórica donde trata de la expresión de caracteres (Rh. 1417a 22). Sobre los conceptos de êthos y páthos en Aristóteles, Cicerón, Dionisio de Halicarnaso, Quintiliano y Ps.-Longino, véase C. Gill, «The Ethos/Pathos Distinction in Rhetorical and Literary Criticism», $C Q$ 34, 1984, pp. 149-66; comentarios sobre el tratamiento del @qoj en varios discursos de distinta naturaleza y fecha pueden leerse en D. A. Russell, «Ethos in Oratory and Rhetoric», en Characterization and Individuality in Greek Literature, Chr. Pelling, ed., Oxford, 1990, pp. 197-212.

14 Reichel, Quaestiones Progymnasmaticae, p. 85.

15 Sobre los discursos, soliloquios y caracterización en Homero, véase M. W. Edwards, Homer Poet of the Iliad, Baltimore y Londres, 1987, pp. 88-97. 
La importancia de Homero en la educación griega durante muchos siglos es un hecho que no necesita ser probado. La presencia de su obra en los ejercicios de escuela, y particularmente en los de preparación retórica, se comprueba tras un breve repaso a las distintas modalidades. En el caso concreto de la etopeya, la obra homérica es la que proporciona el mayor número de modelos. El juicio de Aristóteles, según el cual todo personaje homérico contiene ? ???, hizo de Homero el modelo más recomendable para la confección de etopeyas ${ }^{16}$. De esa opinión fue Teón y seguramente también otros autores de manuales de época imperial. Así, Hermógenes y Aftonio incluyen ejemplos homéricos, pero en la misma proporción proponen como modelos otros autores recomendados por Teón (Menandro, Platón y Jenofonte), y también algún comediógrafo (Éupolis) y oradores (Demóstenes y Aristides). La influencia de los textos homéricos sobre la preceptiva se hace especialmente evidente en el caso de la etopeya emotiva o "patética", aunque la brevedad de los manuales de ejercicios de preparación retórica tampoco permite aquí extraer conclusiones definitivas. Tras la afirmación de Teón de que la etopeya es un ejercicio expositivo de caracteres y emociones, pronto se confirma la división entre etopeya "ética" y "patética" ya presente en otros ejercicios, y en los manuales los ejemplos de la última se entresacan sólo de Homero. A nuestro juicio, dada su fuerza caracterizadora, los lamentos ante los cadáveres de Patroclo (Briseida y Aquiles) y, en especial, de Héctor (Andrómaca, Hécuba y Helena), contribuyeron mucho a la consolidación del tipo "patético", mientras que en los manuales no se citan ejemplos procedentes de un género tan propicio para ello como era la tragedia. Por el contrario, en el caso de la "idolopeya" los ejemplos homéricos tardan algunos siglos más en ser incluidos en los manuales, a pesar de contar con el modelo de la visita de Odiseo al inframundo; habrá que esperar hasta Juan de Sardes y Doxopatros, comentaristas bizantinos de los ejercicios de Aftonio, para encontrar un mayor número de ejemplos de etopeyas procedentes de Ilíada y Odisea. Parece como si el interés por el estudio de Homero y las preferencias por la etopeya en época bizantina hubieran hecho de Homero - junto con la tragedia de Eurípides - casi el único modelo literario pagano para el

16 No olvidemos que el ejercicio tal y como lo define Teón debe bastante a Aristóteles, en especial los criterios de división tipológica: edad, sexo, ocupación, fortuna, etc. (cf., por ejemplo, Rh. 1389a-92a y 1408a 10 y ss.); con todo, algunos de estos criterios de división tipológica son, probablemente, anteriores a Aristóteles (cf. Pl., Ion 540b). 
ejercicio, como por otra parte demuestran los ejercicios prácticos conservados y la naturaleza de algunos comentarios tardíos de la epopeya homérica.

\section{Ejercicios prácticos de etopeya con tema del ciclo troyano}

Ofrecemos a continuación una lista de etopeyas conservadas que presentan temática del ciclo troyano. No incluimos las composiciones que, además de estilo directo (mimético), presentan estilo narrativo (diegemático), entre las que se cuentan numerosas paráfrasis gramaticales y retóricas; tampoco forman parte de la lista ni etopeyas escritas en latín ${ }^{17}$, ni declamaciones como la Embajada ante Aquiles de Elio Aristides (Or. 52) o el Príamo de Coricio de Gaza (decl. 2) ${ }^{18}$, aunque incluimos el Fénix de Procopio de Gaza (decl. 7) por considerarlo en realidad una etopeya ${ }^{19}$. Hemos ordenado las composiciones etopéyicas según traten un tema prehomérico, homérico o posthomérico. Que el tema sea homérico no quiere decir que Homero desarrolle la misma situación, sino que lo tratado en la composición se incluye dentro de la secuencia narrativo-temporal de la obra homérica; cuando la misma situación ya ha sido desarrollada por Homero, marcamos la composición con asterisco $(*)$. Dentro de los dos primeros grupos (tema prehomérico y homérico), la ordenación seguirá la secuencia narrativo-temporal de los acontecimientos en Ilíada y Odisea; por razones obvias, para el tercer grupo, el de composiciones de tema posthomérico, hemos preferido hacer la ordenación según el personaje protagonista. También hemos indicado los casos en que los ejercicios están escritos en verso, en su mayoría hexámetros dactílicos, aunque tres composiciones aparecen escritas en trímetros yámbicos.

\footnotetext{
17 No faltan ejemplos de etopeya con esta temática: ¿Qué diría Aquiles en la sala de doncellas cuando escuchara la tuba de Diomedes? (A. Riese, Anthologia Latina siue Poesis Latinae supplementum, vol. 1, Amsterdam, 1973, reimpr. de Leipzig, 1894, carmen 198, pp. 162-5); y Qué diría Tetis al ver a Aquiles muerto y Qué diría Menelao al ver Troya arrasada por las llamas de Enodio (Dict. 25-6; Fr. Vogel,Magni Felicis Ennodi opera, Berlín, 1961, reimpr. de Berlín, 1885, pp. 174-5 y 289).

18 W. Dindorf, Aristides ex recensione, Hildesheim, 1964, reimpresión de Leipzig, 1829, vol. 2, pp. 584-608; R. Foerster y E. Richtsteig, Choricius Gazaeus Stuttgart, 1972, reimpresión de Leipzig, 1929, pp. 152-74.

19 Debemos recordar que la etopeya es esencial para la confección de declamaciones (cf. Quint. Inst. 3.8, 51). Sobre etopeya y declamación, véase D. A. Russell, Greek Declamation, Cambridge, 1983, pp. 11-2; sobre la presencia del carácter en las declamaciones, pp. 87-105.
} 
Tras la referencia, la edición manejada y el título de la etopeya (original o supuesto por autores de lemas y editores modernos), mencionamos los pasajes, sean o no homéricos, que han inspirado la composición o servido de modelo compositivo al autor del ejercicio ${ }^{20}$. Por lo demás, aunque no siempre es fácil determinar la verdadera naturaleza de cada composición, conviene recordar que en la lista se incluyen unos pocos ejercicios de escuela compuestos por alumnos, algunos modelos de profesores, numerosas composiciones retóricas y textos cuya naturaleza podría considerarse "literaria" 21.

Autores y obras citados: Libanio (s. IV d.C.), Severo (IV d.C.), Procopio de Gaza (V-VI d.C.), Dióscoro de Afrodito (VI d.C.), Nicéforo Basilaces (XII d.C.), Juan Graso (XIII d.C.); los epigramas de la Antología Palatina $(A P)$ aquí citados $^{22}$ han sido fechados entre los s. III-VI d.C.

Papiros y otros materiales: P.Ryl. III 487 (s. III-IV d. C.); P.Vindob. 29789 (III-IV); P.Graves (P[ack $]^{2} \mathrm{n}^{\circ} 1844$, s. IV d. C.); P.Oxy. XLII 3002 (IV d. C.); Díptico de El Cairo ( ${ }^{2}$ $\mathrm{n}^{\circ} 1843$, s.V-VI d. C.); P.Heidelberg $1271 \mathrm{v}\left(\mathrm{P}^{2} \mathrm{n}^{\circ} 1611\right.$, VI d. C.), el único cuya naturaleza puramente escolar no es puesta en $\mathrm{duda}^{23}$; P.Cair.Masp. III 67316 v y P.Car.Masp. III 67353 v (Dióscoro, VI d. C.).

\section{TEMA PREHOMÉRICO}

Severo, eth. 4 (C. Waltz, Rhetores Graeci, vol. 1, Stuttgart y Tubinga [1832], pp. 5434 y A. Staudacher, «Severus von Alexandreia. Ein verschollener griechischer Schriftsteller des IV. Jhr. n. Chr. IV. Die Ethopoiie: ? ?a? ?? e?p???????? ? e???a?? t?? ?? ?e???d??? t?? ??????? ??p?sa?t??;», Byzantinisch-Neugriechische Jahrbücher X, 1932-3, pp. 321-4): ¿Qué diría Menelao después de raptar Alejandro a Helena?. cf. Il. III 351-4.

Lib. eth. 14 (R. Foerster, Libanii Opera, vol. VIII: Progymnasmata. Argumenta orationum demosthenicarum, Leipzig, 1915, pp. 405-8): «¿Qué diría Quirón tras escuchar

\footnotetext{
20 Algunos de esos modelos habían pasado inadvertidos a editores y comentaristas. Dejamos para otra ocasión el estudio exhaustivo del empleo del léxico y la temática homéricos en estas composiciones.

21 Sobre la necesidad de distinguir entre ejercicios puramente escolares, textos para la escuela y ejercicios de naturaleza retórica, véase Cribiore, Writing, Teachers and Students in Graeco-Roman Egypt, p. 28 y ss., y Morgan, Literate education..., p. 40 y ss., y 200 y ss. Sobre la naturaleza de las etopeyas hexamétricas conservadas en papiro y otros materiales, véase Fernández Delgado, «Hexametrische-Ethopoiíai...».

22 Sobre las etopeyas hexamétricas presentes en la Antología, véase G. Guidorizzi, «Gli epigrammi papiracei di epoca imperiale», en Atti del XVII Congresso Internazionale di Papirologia, Nápoles, 1984, pp. 313-7.

23 cf. Cribiore, Writing, Teachers and Students in Graeco-Roman Egypt, p. 52.
} 
que Aquiles vivía entre doncellas?».

\section{TEMA HOMÉRICO}

\section{Ilíada, Canto I}

*P.Oxy. XLII 3002: «Palabras de Atenea para detener a Aquiles cuando va a echar mano a su espada y atacar a Agamenón» (hexámetros). La composición está a medio camino entre la etopeya y la paráfrasis, otro ejercicio escolar. Su autor parafrasea en verso $^{24} \mathrm{Il}$. I 207-14, aunque, como ocurre en muchos casos, el número de versos que influye directamente sobre la composición es algo mayor (Il. I 190-224).

Severo, eth. 5 (Waltz, Rhetores Graeci, vol. 1, p. 544 y Fr. P. Karnthaler, «Severus von Alexandreia. Ein verschollener griechischer Schriftsteller des IV. Jhr. n. Chr. II.

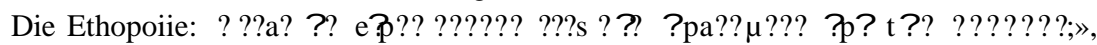
Byzantinisch-Neugriechische Jahrbücher VIII, 1929-30, pp. 327-30): «¿Qué diría Briseida llevada por los heraldos?». cf. Il. I 348, Il. XIX 287-300 e Il. IX 343.

Lib. eth. 15 (Foerster, Libanii Opera, vol. 8, pp. 408-11): «¿Qué diría Aquiles cuando le arrebataron a Briseida?». En Il. I 340 y ss. los heraldos se llevan a Briseida.

Canto III

AP 9.475 (P. Waltz y G. Soury, Anthologie Grecque. Première Partie Anthologie Palatine tome VIII (Livre IX, Épigr. 359-827); París, 1974, p. 56): «¿Qué diría Helena al ver combatir a Menelao y Paris?». Il. III 154 y ss. e Il. III 340 y ss.

\section{Canto IV}

AP 9.464 (Waltz-Soury, Anthologie Grecque, p. 53): «¿Qué diría Pándaro cuando Menelao es herido?» (hexámetros). Il. IV 95 y ss.

\section{Canto V}

*P.Heidelberg 1271 v, frag. IV, líneas 19-29 (G. A. Gerhard y O. Crusius, «Mythologische Epigramme in einem Heidelberger Papyrus», en Mélanges Nicole, Ginebra, 1905, p. 618): «Zeus cuando Afrodita llega a su lado y acusa a Diomedes de haberla herido en la mano» (hexámetros). Il. V 428-30.

\section{Canto IX}

AP 9.467 (Waltz-Soury, Anthologie Grecque, p. 54): «¿Qué diría Peleo al saber que Aquiles ha dejado el combate?» (hexámetros). En Il. IX 252-9 Odiseo recuerda a Aquiles los consejos de su padre (el mismo tema es tratado con mayor brevedad por Néstor en Il. XI 783-4) y en Il. IX 438 y ss. con el discurso de Fénix.

*P.Heidelberg $1271 \mathrm{v}$, frag. I, líneas 1-7 (Gerhard-Crusius, «Mythologische Epigramme in einem Heidelberger Papyrus», p. 617): «Fénix, durante la embajada, tratando de persuadir a Aquiles para que cese en su cólera» (hexámetros). Il. IX 433-605; cf. Il. XI 831.

24 Es el único ejemplo conservado de paráfrasis en verso (cf. Fernández Delgado, Hexametrische-Ethopoiíai..., p. 302). 
AP 9.465 (Waltz-Soury, Anthologie Grecque, p. 53): «¿Qué diría Altea para persuadir a Meleagro?» (hexámetros). cf. Il. IX 584-5.

\section{Canto XI}

AP 9.457 (Waltz-Soury, Anthologie Grecque, pp. 50-1): «¿Qué diría Aquiles cuando es herido Agamenón?» (hexámetros). cf. Il. XI 251 y ss., Il. XVI 26 e Il. XVI 49-100.

\section{Canto XIV}

Lib. eth. 4 (Foerster, Libanii Opera, vol. 8, pp. 381-4): «¿Qué diría Aquiles ante la derrota de los griegos?». cf. Il. XIV 139-41.

\section{Canto XVI}

P.Heidelberg 1271 v, frag. III, líneas 16-8 (Gerhard-Crusius, «Mythologische Epigramme in einem Heidelberger Papyrus», p. 618): «Un griego tras haber dado muerte Héctor a Patroclo y despojarlo de sus armas» (hexámetros). cf. Il. XVI 844-54.

AP 9.476 (Waltz-Soury, Anthologie Grecque, p. 56): «¿Qué diría Héctor a Patroclo por no haber podido portar éste la lanza de Aquiles?» (trímetros yámbicos). cf. Il. XVI 140-4, Il. XVII 130 ss. y 189 y ss.

\section{Canto XVIII}

*Lib. eth. 3 (Foerster, Libanii Opera, vol. 8, pp. 379-81): «¿Qué diría Aquiles ante el cadáver de Patroclo?». Il. XVIII 324-42; cf. Il. XXIII 84-92.

*P.Car.Masp. III 67353 v (Dióscoro de Afrodito): «Lo que habría dicho Aquiles al pedirle a Tetis las armas» (sólo se conserva el título). Il. XVIII 79 y ss.

\section{Canto XIX}

*AP 9.460 (Waltz-Soury, Anthologie Grecque, p. 52): «¿Qué diría Aquiles al ver las armas (que le procuró su madre)?» (hexámetros). Il. XIX 18 y ss.

AP 9.473 (Waltz-Soury, Anthologie Grecque, p. 55): «QQué diría Agamenón al ver a Aquiles armado?» (hexámetros). cf. Il. XIX 56 y ss. y XIX 364-91.

AP 9.463 (Waltz-Soury, Anthologie Grecque, p. 53): «¿Qué diría Héleno al ver a Aquiles con armas?» (hexámetros). cf. Il. XIX 56 y ss., 364-91 o Il. XXII.

Procop.Gaz., decl. 7 (A. Garzya y R. J. Loenertz, Procopii Gazaei Epistolae et Declamationes, Ettal, 1963, pp. 97-8): Fénix, que trata el tema «¿Qué diría Fénix después de su fracaso en la embajada y cuando Aquiles ayuda a los griegos nada más enviar Agamenón a Briseida ataviada como suplicante?». Naturalmente el momento es algo posterior a Il. XIX 146 y ss., donde Aquiles anuncia a los aqueos su deseo de volver al combate, e Il. XIX 282 y ss., donde aparece Briseida.

\section{Canto XXIV}

*Lib. eth. 2 (Foerster, Libanii Opera, vol. 8, pp. 376-8): «¿Qué diría Andrómaca ante el cadáver de Héctor?». Il. XXIV 725-45; cf. Il. XXII 477-514 e Il. VI 407-65.

Severo, eth. 6 (Waltz, Rhetores Graeci, vol. 1, pp. 544-5): «¿Qué diría Héctor al enterarse en el Hades de que Príamo comió con Aquiles?». cf. Il. XXIV 592-5. 
Odisea, canto IV:

Lib. eth. 21 (Foerster, Libanii Opera, vol. 8, pp. 421-3): «¿Qué diría Menelao al enterarse de la muerte de Agamenón?». En Od. IV 512-47, Proteo cuenta a Menelao lo ocurrido a Agamenón; Menelao reacciona con desesperación; y Proteo intenta calmarlo diciéndole que nada puede hacer para ayudar a Agamenón. Sobre ello, véase también E. Or. 360 y ss., donde, como en la etopeya de Libanio, las palabras aparecen puestas en boca de Menelao.

\section{Canto IX}

Lib. eth. 23 (Foerster, Libanii Opera, vol. 8, pp. 425-9): «QQué diría Odiseo encerrado en la cueva del cíclope?». cf. $O d$. IX 371 y ss., y $O d$. IX 316-8, Od. IX 299-306 y $O d$. IX 420-4.

Lib. eth. 24 (Foerster, Libanii Opera, vol. 8, pp. 429-31): «¿Qué diría Odiseo al ver al cíclope comerse a sus compañeros?». cf. $O d$. IX 475-9. En el momento en que sus compañeros son devorados Odiseo no responde al cíclope (Od. IX 294 y ss.).

\section{Canto XI}

*AP 9.459 (Waltz-Soury, Anthologie Grecque, p. 51): «¿Qué diría Aquiles al ver a Odiseo en el Hades?» (hexámetros). Od. XI 467 y ss.

Severo, eth. 7 (Waltz, Rhetores Graeci, vol. 1, 545-6 y O. Schissel, «Severus von Alexandreia. Ein verschollener griechischer Schriftsteller des IV. Jhr. n. Chr.», Byzantinisch-Neugriechische Jahrbücher VIII, 1929-30, pp. 10-3): «¿Qué diría Aquiles al enterarse en el Hades de que Pirro destruyó Troya?». cf. Od. XI 533-4.

Nicéforo Basilaces, eth. 4 (Waltz, Rhetores Graeci, vol. 1, pp. 473-5 y A. Pignani, Niceforo Basilace. Progimnasmi e monodie. Testo critico, introduzione, traduzione a cura di ..., Nápoles, 1983, pp. 188-91): «¿Qué diría Ayante al ver a Odiseo con forma corpórea en el Hades?». cf. Od. XI 543 y ss.

AP 9.470 (Waltz-Soury, Anthologie Grecque, p. 55): «¿Qué diría Aquiles (en el Hades) tratando de calmar la cólera de Ayante?» (hexámetros). cf. Od. XI 553-62.

\section{Canto XIII}

*AP 9.458 (Waltz-Soury, Anthologie Grecque, p. 51): «QQué diría Odiseo al desembarcar en Ítaca?» (hexámetros). Od. XIII 352 y ss.

AP 9.471 (Waltz-Soury, Anthologie Grecque, p. 55): «¿Qué diría Néstor al saber que Odiseo había logrado el regreso?» (hexámetros). cf. $O d$. III y $O d$. I 1 y ss.

AP 9.472 (Waltz-Soury, Anthologie Grecque, p. 55): «¿Qué diría Néstor a Odiseo al saber de su regreso?» (hexámetros). cf. $O d$. III y $O d$. I 1 y ss.

Canto XXI

*P.Ryl. III 487 (E. Heitsch, Die griechischen Dichterfragmente der römischen Kaiserzeit, Gotinga, 1963, vol. 1, pp. 77-9, fr. XXI): «Odiseo habla al porquerizo Filecio y le pide ayuda» (hexámetros). Od. XXI 207-41.

\section{Canto XXIV}


Lib. eth. 25 (Foerster, Libanii Opera, vol. 8, pp. 431-4): «¿Qué diría Odiseo tras dar muerte a los pretendientes?». cf. $O d$. XXIV.

\section{TEMA POSTHOMÉRICO}

Aquiles y la toma de Troya

Lib. eth. 12 y 13 (Foerster, Libanii Opera, vol. 8, pp. 401-3 y 403-5): «¿Qué diría Aquiles enamorado de Pentesilea una vez muerta?».

Dióscoro de Afrodito, P.Cair.Masp. III 67316 v (L. S. B. Mac Coull, Dioscorus of Aphrodito. His Work and his World, Berkeley-Londres, 1989, pp. 129-30): «¿Qué diría Aquiles muerto a causa de Políxena?» (hexámetros).

P.Graves, frag. I (Heitsch, Die griechischen Dichterfragmente der römischen Kaiserzeit, vol. 1, p. 86, fr. XXVI, 1 r, vv. 9 y ss.): «¿Qué diría Calíope para consolar a Tetis?» (hexámetros). cf. Q.S. 3.608-30, cuyos modelos homéricos son Il. XVIII 95 e Il. XXIV 540.

AP 9.478 (Waltz-Soury, Anthologie Grecque, p. 57): «¿Qué diría Príamo a Héleno?» (trímetros yámbicos).

AP 9.461 (Waltz-Soury, Anthologie Grecque, p. 52): «¿Qué diría Pirro al tomar Troya?» (hexámetros). cf. Od. XI 492-3 y Od. XI 506-37; cf. Q.S. 7.701-4.

AP 9.462 (Waltz-Soury, Anthologie Grecque, p. 52): «¿Qué diría Deidamía cuando Pirro destruyó Troya?» (hexámetros).

Díptico de El Cairo (s.V-VI d. C.) (Heitsch, Die griechischen Dichterfragmente der römischen Kaiserzeit, vol. 1, p. 89, fr. XXXVIII): «Cuando, tras la conquista de Troya, los griegos se disponen a regresar a su patria, la sombra de Aquiles aparece sobre su tumba reclamando su parte del botín» (hexámetros). E. Hec. 109-15.

Lib. eth. 16 (Foerster, Libanii Opera, vol. 8, pp. 411-2): «QQué diría Políxena cuando los griegos le ordenan que se ponga en marcha diciéndole que va a ser la esposa de Aquiles?». Hécuba de Eurípides; cf. entre otros los versos 342-4.

Juan Graso I (M. Gigante, Poeti Italo bizantini del secolo XIII, introduzione, testo crítico e commentario di ..., Nápoles, 1953, pp. 51-3): «¿Qué diría Hécuba tras la destrucción de Troya?» (trímetros yámbicos). Troyanas y Hécuba de Eurípides (cf. especialmente Tro. 1272-330); y la Alejandra de Licofrón.

Ayante

Lib. eth. 7 (Foerster, Libanii Opera, vol. 8, pp. 389-91): «¿Qué diría Ayante privado de las armas?». Ayante de Sófocles. Sobre el juicio por las armas de Aquiles y la confrontación entre Ayante y Odiseo, pueden mencionarse el Ayante y el Odiseo de Antístenes (L. Radermacher, Artium scriptores ..., pp. 121-6), las intervenciones de Ayante y Odiseo durante el juicio en el libro XIII de las Metamorfosis de Ovidio, y las palabras de ambos héroes en las Posthoméricas de Quinto de Esmirna (5.180 y ss.).

Lib. eth. 6 (Foerster, Libanii Opera, vol. 8, pp. 386-9): «QQué diría Ayante tras recu- 
perar la razón?». Ayante de Sófocles.

Lib. eth. 5 (Foerster, Libanii Opera, vol. 8, pp. 384-6): «QQué diría Ayante cuando se disponía a suicidarse?». Ayante de Sófocles. cf. especialmente los versos 430-80.

P.Graves, frag. II (s. IV d. C.) (Heitsch, Die griechischen Dichterfragmente der römischen Kaiserzeit, vol. 1, p. 87, fr. XXVI, 2 r, vv. 3-5): «¿Qué diría Odiseo al dar Menelao orden de no enterrar a Ayante?» (hexámetros). Ayante de Sófocles. Las intervenciones de Menelao y Odiseo pueden leerse desde los versos 1162 y ss.

Agamenón

P.Heidelberg 1271 v, frag. VI, líneas 34-45 (Gerhard-Crusius, «Mythologische Epigramme in einem Heidelberger Papyrus», pp. 618-9): «El fantasma de Agamenón ante la falta de ayuda a Orestes por parte de Menelao» (hexámetros). E. Or. 642-79.

P.Vindob. 29789: «¿Qué diría Clitemestra a Orestes?». cf. S. El. 1405 y ss. y 525 y ss.; E. El. 1165,1215 y 1011 y ss., Or. 827-30.

Diomedes

P.Heidelberg 1271 v, frag. V, líneas 30-3 (Gerhard-Crusius, «Mythologische Epigramme in einem Heidelberger Papyrus», p. 617): «Afrodita cuando Diomedes es herido por Egialea» (hexámetros).

Helena

AP 9.474 (Waltz-Soury, Anthologie Grecque, p. 56): «QQué diría Idótea al ver a Helena en Faros?» (hexámetros). E. Hel. 993 y ss.; cf. Od. IV 365.

P.Heidelberg 1271 v, frag. II, líneas 8-15 (Gerhard-Crusius, «Mythologische Epigramme in einem Heidelberger Papyrus», pp. 617-8): «Una mujer griega que se encuentra con Helena en Grecia» (hexámetros). cf. E. Or. 56-60.

Los autores de etopeyas prefieren en general la temática homérica, sobre todo los episodios de los primeros y últimos cantos de Ilíada, la parte más conocida de la obra en la Antigüedad. Y como es natural, siguen las propuestas teóricas y los modelos incluidos en los manuales de ejercicios de preparación retórica cuando elaboran lamentos ante los cadáveres de Héctor y Patroclo ${ }^{25}$, abordan situaciones producidas durante la embajada ante Aquiles ${ }^{26}$, y componen intervenciones puestas en boca de los compañeros muertos de Odiseo durante la visita del héroe al inframundo ${ }^{27}$. Muchas de las situaciones tratadas son similares a las que podían leerse en Homero, aunque en no pocos casos los autores desarrollan alguna otra inspirada en la obra

25 Lib. eth. 2 y 3.

26 P. Heidelberg 1271 v, frag. I, líneas 1-7; cf. también AP 9.465 y 467, y Proc. Gaz., decl. 7.

27 AP 9.459 y 470; Severo, eth. 7; Nicéforo Basilaces, eth. 4. 
homérica. Cuando así ocurre, unas veces los compositores se preocupan por delinear los caracteres en situaciones de gran trascendencia o especialmente señaladas, como cuando Briseida es llevada por los heraldos, Aquiles recibe las armas o aparece en el campo de batalla armado con ellas; y en las etopeyas de temática posthomérica, cuando tras la caída de Troya intervienen Hécuba o Pirro. Otras veces las situaciones parecen sugeridas por el propio Homero, sea directamente o por medio de sus silencios. Así, en Lib. eth. 4 «¿Qué diría Aquiles ante la derrota de los griegos?», Libanio da cuerpo a la opinión de Néstor cuando en Il. XIV 139-41 se dirige éste a Agamenón en los siguientes términos: «AAtrida! Seguro que ahora el maldito corazón de Aquiles está alegre en el pecho, contemplando el asesinato y la fuga de los aqueos, pues no tiene ni el más mínimo sentimiento» ${ }^{28}$; y en Severo, eth. 6 , «¿Qué diría Héctor al enterarse en el Hades de que Príamo comió con Aquiles?», "idolopeya" cuyo argumento encuentra su origen en las palabras de Aquiles en $I l$. XXIV 592-5, donde el héroe pide a Patroclo ya muerto que no se enoje con él si se entera de que a cambio de rescate ha entregado el cadáver de Héctor a Príamo. Así pues, las palabras de reproche dirigidas por el fantasma de Héctor a su padre por haber cenado con Aquiles representan la "versión troyana" de la reacción ante un encuentro tan inesperado. Los silencios de Briseida al ser llevada por los heraldos en Il. I 348 y de Ayante ante las palabras de Odiseo en $O d$. XI 563 suponen un reto al que, respectivamente, dan respuesta Severo, eth. 5 y Nicéforo Basilaces, eth. 4; también la callada alegría de Aquiles en $O d$. XI 540 al saber de los éxitos de su hijo es expresada por medio de la palabra en Severo, eth. 7. Por lo demás, algunas composiciones pueden haber tenido como modelo episodios de los poemas cíclicos, si bien el análisis de las mismas revela en algunos casos su gran dependencia del material homérico. Eso ocurre, por ejemplo, con Severo, eth. 4, «¿Qué diría Menelao después de raptar Alejandro a Helena?», composición que sigue principalmente los argumentos puestos en boca de Menelao y dirigidos a Paris en Il. III 351-4.

Por otra parte, nada de extraño tiene que la tragedia, a pesar de no aparecer recomendada a tal efecto por los autores de manuales de ejercicios de preparación retórica ${ }^{29}$, proporcione abundantes modelos a la etopeya de te

28 Cuando citamos traducciones españolas, salvo mención expresa, utilizamos las de la Biblioteca Clásica Gredos.

29 A este respecto, cabe decir que la crítica negativa que Teón dirige a Eurípides por su 
ma posthomérico, sobre todo cuando en la elaboración del ejercicio acaba imponiéndose el tipo "patético", y cuando la representación de las tragedias ya había quedado reducida al recitado o canto de algunos pasajes de gran patetismo (especialmente monólogos). Según Viljamaa, una de las formas en que debió de practicarse la etopeya fue la canción de lamento, cuya fuente y origen fueron lamentos poéticos, especialmente trágicos ${ }^{30}$. Además, la tragedia es, junto a la épica homérica, el género literario más imitado por los autores bizantinos. El tragediógrafo más apreciado en esta época es Eurípides. Y aunque no siempre ha sido vista, la influencia de su tragedia se observa fácilmente en la etopeya, en particular la de las obras que configuran la llamada tríada bizantina, Orestes, Hécuba y Fenicias. Así, podemos citar Lib. eth. 22 («¿Qué diría Meneceo al tomar la decisión de quitarse la vida para que su patria consiguiese la victoria?», etopeya inspirada en E. Ph. 985-1018 ${ }^{31}$; P.Heidelberg $1271 \mathrm{v}$, frag. VI «El fantasma de Agamenón ante la falta de ayuda a Orestes por parte de Menelao», cuyo modelo es Orestes, en concreto los versos 642-79, donde Orestes pide a Menelao que, en pago a la deuda contraída con Agamenón, salve su vida, y en su petición emplea argumentos luego utilizados en el ejercicio escolar y acaba diciéndole a Menelao: « Tí́o, hermano de sangre de mi padre, piensa que el muerto escucha bajo tierra estos ruegos, que su alma revolotea sobre ti, y que te dice cuanto yo te digo!»; P.Heidelberg 1271 v, frag. II «Una mujer griega que se encuentra con Helena en Grecia», inspirada igualmente en Orestes (especialmente $O r$. 56-60 y 1302-10), al igual que Lib. eth. 21 («¿Qué diría Menelao al enterarse de la muerte de Agamenón?»), que revela conocimiento de Or. 360 y ss.; el

inadecuada caracterización de Hécuba al presentarla filosofando en momentos inoportunos (2.60 Sp.), aunque de modo indirecto, tal vez sugiere el empleo de la tragedia como modelo para la etopeya.

30 Viljamaa, Studies in Greek Encomiastic Poetry of the Early Byzantine Period, p. 21.

31 Sobre la preferencia de los antiguos por las Fenicias de Eurípides, véase J. M. Bremer, «The Popularity of Euripides' Phoenissae in Late Antiquity», en Proceedings of the VII ème Congrès de la F.I.E.C., J. Harmatta, ed., Budapest, 1984, vol. 1, pp. 281-8; véanse también las tablas $\mathrm{n}^{\mathrm{o}} 22$ y 23 incluidas en Morgan, Literate education... Sobre la tradición de Eurípides, véanse G. Zuntz, An inquiry into the transmission of the plays of Euripides, Cambridge, 1965, y A. Tuilier, Recherches critiques sur la tradition du texte d'Euripide, París, 1968. Muy útiles trabajos de carácter general sobre el destino de la poesía griega en Bizancio son el de H. Hunger, «On the imitation (Mimesis) of Antiquity in Byzantine Literature», DOP 23-24, 1969, pp. 14-38 y el de A. Bravo García, «Sobre el destino de la poesía griega en Bizancio», Erytheia 7, 1986, pp. 303-21. 
Díptico de El Cairo, en el que el fantasma de Aquiles se dirige a los griegos, cuyo modelo indiscutible es E. Hec. 109-15; Lib. eth. 16 («¿Qué diría Políxena cuando los griegos le ordenan que se ponga en marcha diciéndole que va a ser la esposa de Aquiles?»), etopeya construida con materiales procedentes de Hécuba. Por su parte, Juan Graso utiliza como fuentes Troyanas y Hécuba en la elaboración de su ejercicio patético «¿Qué diría Hécuba ante Troya destruida?». También otras etopeyas parecen depender de la tragedia: P.Graves, frag. II («¿Qué diría Odiseo al dar Menelao orden de no enterrar a Ayante?»), de Ayante de Sófocles; P.Vindob. 29789 («¿Qué diría Clitemestra cuando Orestes se disponía a atacarla?»), de varias tragedias (cf. S. El. 1405 y ss. y 525 y ss.; E. El. 1165, 1215 y 1011 y ss., Or. 827-30); AP 9.474, de Helena de Eurípides; Lib. eth. 5, 6 y 7, del Ayante de Sófocles; Lib. eth. 1 (y en parte tal vez eth. 17), de Medea de Eurípides; y Nicéforo Basilaces, eth. 23 («¿Qué diría Adrasto cuando, tras la victoria de los tebanos, éstos no permiten dar sepultura a los argivos muertos en combate?»), de Suplicantes de Eurípides, y eth. 15 («¿Qué diría Heracles cuando Zeus le vaticina que un muerto le dará muerte?»), de Traquinias de Sófocles (cf. v. 1143 y ss.). Por lo demás, la intervención del fantasma de Polidoro en la Hécuba de Eurípides (vv. 1-58) será recordada por los rétores posteriores como ejemplo de "idolopeya" (Doxopatros $2.496 \mathrm{~W}$ ). Incluso cabe explicar la utilización del trímetro yámbico en algunos ejemplos de etopeya como consecuencia directa de esa influencia del género trágico.

Si analizamos las composiciones según criterios estrictamente retóricos, observamos que sus autores practican sobre todo etopeyas "simples", es decir, monólogos ${ }^{32}$, etopeyas "de personaje determinado" y etopeyas "patéticas"; en general las etopeyas, como a excepción de Teón recomiendan todos los rétores, presentan una estructura temporal más o menos fija (presentepasado-[breve vuelta al presente]-futuro) ${ }^{33}$, aunque no faltan excepciones, en especial entre las etopeyas en verso, las de tono menos patético y las que no parecen obras de rétores. Son igualmente frecuentes las "idolopeyas" ${ }^{34}, \mathrm{y}$

32 cf. Hermog. 20-1 R.

33 cf. Hermog. 21-2 R. y Aphth., 2.45 Sp.; la transición al futuro desde el pasado mediante una breve vuelta al presente aparece recomendada y ejemplificada en Nicol., $3.490 \mathrm{Sp}$. y Emporio 563 H. Sobre ello, cf. O. Schissel, «Libanios Ethopoiie 22», Hermes, 74, 1939, pp. $111-2$.

34 P. Heidelberg 1271 v, frag. VI, líneas 34-45; Díptico de El Cairo; Severo, eth. 6 y 7; 
encontramos, asimismo, ejemplos de etopeya "de personaje indeterminado" ${ }^{35}$. Por lo demás, las composiciones están repletas de exhortaciones, interrogaciones y exclamaciones, y su principal recurso de estilo es el asíndeton, reforzado en ocasiones por la anáfora y el isocolon ${ }^{36}$. En su manual, el rétor Teón aconseja emplear en la etopeya un estilo acorde con la naturaleza y situación del personaje (2.115-6 Sp.), al igual que hace Hermógenes (21-2 R.); en cambio, Aftonio recomienda un estilo «claro, conciso, florido (en el sentido de vigoroso), suelto y libre de cualquier artificio y figura» (2.45 Sp.). A nuestro juicio, el tono patético de la mayor parte de las etopeyas hizo que los recursos apropiados para conseguir p???? predominaran sobre los demás ${ }^{37}$, tanto en la práctica del ejercicio como en su preceptiva teórica, y no

AP 9.459 y 470; Dióscoro de Afrodito, P.Cair.Masp. III 6731 v; Nicéforo Basilaces, eth. 4. También hallamos algunos ejemplos de lo que puede considerarse "prosopopeya", aunque éstos no presentan el encabezamiento propio del ejercicio o forman parte de una composición en estilo narrativo, razones por las cuales no han sido incluidos en nuestro catálogo. Nos referimos a las intervenciones de Valentía ante la injusticia sufrida por Ayante en el juicio por las armas (AP 7.145-6), y a la breve intervención de las propias armas dentro de otra composición (AP 9.116, v. 3).

35 P.Heidelberg $1271 \mathrm{v}$, frag. II, líneas 8-15; frag. III, líneas 16-8; y tal vez AP 9.463.

36 Es frecuente encontrar estos recursos en las etopeyas de Libanio, cf. Schouler, La tradition hellenique chez Libanios, vol. 1, pp. 123-4.

37 Ya Viljamaa se percató de que, para la confección de la etopeya y para la composición de otros géneros encomiásticos que incluyen algún lamento, como es el caso de la monodia, los manuales retóricos antiguos ofrecen las mismas recomendaciones acerca del estilo y de la división temporal (Studies in Greek Encomiastic Poetry of the Early Byzantine Period, pp. 117-8). Como hipótesis explicativa nosotros sugerimos la siguiente: tal vez el rétor Aftonio entendió como de aplicación general a todas las etopeyas el precepto acerca de la elaboración de éstas en tres ejes temporales tal y como la presenta Hermógenes, quien, más bien, parece aplicarla únicamente a la "etopeya mixta" de Aquiles ante el cadáver de Patroclo; en cualquier caso, tanto Hermógenes como Aftonio presentan esa división temporal inmediatamente después de tratar sobre la "etopeya patética" y la "etopeya mixta", de modo que tal vez ambos rétores podrían estar recomendándola sólo para estos dos tipos de etopeya de tono emotivo. Posteriormente, la gran influencia que, por razones de brevedad y claridad, y por el hecho de presentar modelos prácticos, ejerció el manual de Aftonio sobre la tradición retórica pudo facilitar la pervivencia de este malentendido. No olvidemos, por otra parte, que el único ejemplo de etopeya que presenta Aftonio es, precisamente, una "etopeya patética" titulada «¿Qué diría Níobe ante los cadáveres de sus hijos?». Por lo demás, el predominio de ejemplos prácticos de tono emotivo generalizó la aplicación de los mencionados preceptos sobre el estilo y la división temporal. También las recomendaciones de estilo ofrecidas por Aftonio (claridad, concisión, etc.), algunas de las cuales nos recuerdan las ,retaì lécewj, deben, a nuestro juicio, referirse principalmente a la "etopeya patética" y a la "etopeya mixta", como sugieren los datos que nos transmiten los autores antiguos sobre recursos que 
sólo en las etopeyas sino también en las declamaciones ${ }^{38}$.

El rétor Libanio y su discípulo Severo compusieron varias etopeyas de tema homérico o del ciclo troyano, y en la práctica del ejercicio ambos muestran un uso peculiar y en parte distinto. Así, Libanio está más interesado que otros autores por la temática de Odisea; aborda en varias de sus etopeyas el tratamiento de un mismo tema: Aquiles enamorado del cadáver de Pentesilea (eth. 12-eth. 13); o presenta momentos próximos: Ayante privado de las armas, una vez recuperada la razón, y cuando se dispone a suicidarse (eth. 7eth. 6-eth. 5); y Odiseo encerrado en la cueva y viendo al cíclope comerse a sus compañeros (eth. 23-eth. 24). Además, en sus composiciones Libanio tiende a ofrecer gran acopio de datos acerca del personaje tratado, rememorando por medio de sus palabras situaciones anteriores que, mejor o peor, vienen al caso. Por contra, Severo compone etopeyas más breves y centradas en una sola intervención del personaje homérico. Por lo demás, es frecuente que los rétores reutilicen los mismos temas tratados por otros rétores anteriormente.

En cuanto a la dicción empleada en las etopeyas, la de las composiciones en verso es épica y fundamentalmente homérica, aunque con algunos términos y giros presentes en la obra de Nono y Quinto de Esmirna. Casi todos los términos y expresiones los hallamos en Homero con la misma o parecida forma, y no pocas veces en la misma sedes métrica. Por otra parte, y ello es algo de gran importancia, los autores se esfuerzan en caracterizar a los personajes no sólo por lo que dicen, sino también por cómo lo dicen. La selección de términos y expresiones puestos en su boca está guiada por el criterio de adecuación al carácter y a la situación homérica. Es decir, el personaje se expresa como lo hace ese mismo u otro personaje parecido, en esa misma o en otra situación parecida en Ilíada y Odisea. En otras ocasiones sus palabras nos recuerdan las que el narrador o algún otro personaje refiere a él o a

procuran páqoj; cf., entre otros, los términos en que se expresa el rétor Menandro al hablar de la monodia (D. A. Russell y N. G. Wilson, Menander rhetor, Londres, 1981, pp. 200-7) y las precisiones de Hermógenes sobre el discurso lastimero (360 R.), aunque, como recuerda Demetrio en Sobre el estilo, determinados recursos de estilo deben ser igualmente empleados en la expresión de emociones y en las descripciones de carácter (L. Radermacher, Demetrii Phalerei qui dicitur de elocutione libellus, Stuttgart, 1967, p. 10).

38 Quintiliano recrimina el uso de comienzos abruptos y llenos de exclamaciones, y recomienda abandonar esa costumbre, al parecer muy extendida entre los rétores (Inst. III 8.58$60)$. 
otro personaje en la misma u otra situación parecida.

Veamos como ejemplo el siguiente ejercicio elaborado por un alumno:

P.Heidelberg $1271 \mathrm{v}$, frag. III, líneas 16-8: [??] t?? ??????? t?? ???t???? f??e?sa?t??t?? ??t?????? ?a?f???sa?t[??t? ?p?a a?t??]?

[??]?t?? ???ste??? $\mu$ ? t?pe???a????'? ????e??

[a]????? ?? pt??? $\mu$ ??? ?e $\mu$ ???? ?????t?? ?? ?t??.

Un griego tras haber dado muerte Héctor a Patroclo y despojarlo de sus armas ${ }^{39}$ : Héctor, no te ufanes con el triunfo, pues mañana en la batalla estará también Aquiles, insaciable en sus deseos de combate.

v. 1 ???t?? ???ste??? $\mu$ ? t??pe?: ???ste???, cf. ???ste?es?e $\mu$ ??es?a? referido a

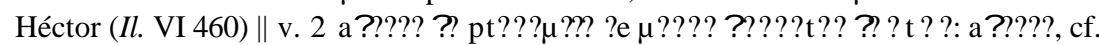
Il. XVIII 269, dicho de Aquiles por el prudente Polidamante, quien recomienda a los

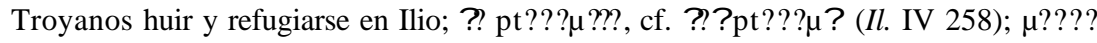
?????t?? ?? ?t ? ?, cf. $\mu$ ???? ?????t?? (Il. XX 2), dicho de Aquiles por Homero.

El pasaje que más ha influido en esta breve composición es $I l$. XVI 84454, con los reproches de Patroclo a Héctor, pero el estudio del léxico demuestra que en la elaboración de la etopeya también han influido los siguientes pasajes: Il. XVIII 269, donde Polidamante expresa sus temores ante la vuelta al combate de Aquiles; las palabras de Homero referidas a Aquiles en Il. XX 2; y el pasaje donde Aquiles se dirige a Héctor en los siguientes términos: ???t??, ?t?? p?? ?f ?? ?at?????' ??e?a?????/ s ? ? ?s ses ?', ? $\mu$ ? d' ??d?? ?p??e? ?? sf?? ???ta / ??p?e ... ( Il. XXII 331 y ss.).

En el caso de los ejercicios en prosa, aunque la vinculación temática con la fuente homérica es igualmente clara, no existe semejanza formal con el modelo, pues los autores componen sus ejercicios en un griego ático literario más o menos logrado, o simplemente en una prosa comprensible para sus contemporáneos, y, por ende, muy alejada de la dicción poética de Home$\mathrm{ro}^{40}$.

Veamos un ejemplo de etopeya en prosa, obra en este caso de un rétor:

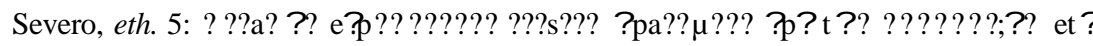

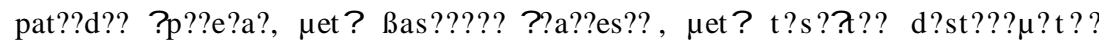

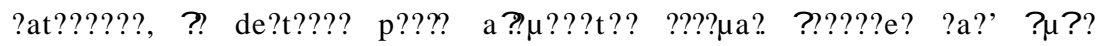

39 J. A. Fernández Delgado y J. Ureña Bracero, Un testimonio de la educación literaria griega en época romana: IG XIV 2012 = Kaibel, EG 618, Univ. de Extremadura, 1991, p. 60.

40 Sobre la dicción de ejercicios escolares y retóricos presentes en papiro, véase Morgan, Literate education..., p. 200 y ss. 
?st?ate???t?, ?a? ?????a d??????t??, ??????e? ?a?' ???????? ?e???as? ?a?p???

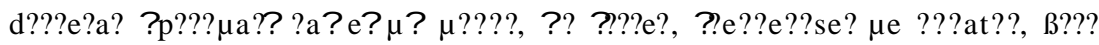
d???e???? pa?seta?

¿Qué diría Briseida llevada por los heraldos?: Tras la destrucción de mi patria, tras la muerte del rey, tras un largo catálogo de desgracias, de nuevo, por segunda vez, soy cautiva de guerra. Los griegos luchaban con nosotros y me convertí en botín de guerra; los griegos se han enfrentado a los griegos, y también soy conducida a la esclavitud. Parece que, si no me libera la muerte, la vida nunca dejará de esclavizarme.

En su comentario a esta etopeya, Karnthaler («Severus von Alexandreia ...», pp. 328-30) menciona de pasada los pasajes homéricos a los que se refiere nuestro texto, concretamente Il. XIX 296, II 692, I 184, I 323 y I 392. Se trata de una etopeya en prosa, "de personaje determinado" y del tipo emotivo; estamos, además, ante una "etopeya simple", a pesar de la opinión de Karnthaler, quien considera las palabras de Briseida dirigidas a Agamenón. En cuanto al tiempo, en el comentario se nos recuerda que en la etope-

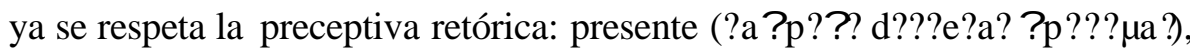
pasado (??????e? - ?e???as?, futuro (?a? e? $\mu$ ? $\mu$ ???? - pa? seta?). También menciona Karnthaler la claridad, concisión y estilo vigoroso, suelto y libre de figuras. Caracteriza, pues, al texto la ?a?a??t?? o claridad expositiva: léxico sencillo, sujetos en nominativo (????t??); se evitan construcciones con participio y especialmente la hipotaxis. No faltan, sin embargo, algunas

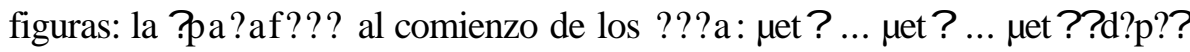
??af??? en ??????e? ... ?a???????e? ?a?, p???pt?t?? en ??????e? ?a?'

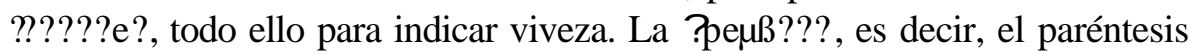
o inserción de la expresión ? ? ????e?, sirve, según el comentarista, para equilibrar la longitud del período, mientras que los ?? ?a breves le confieren vivacidad.

Ciertamente en la etopeya Severo trata de caracterizar a una mujer, concubina, esclava desafortunada, que expresa sus desgracias, pero no a cualquier mujer desgraciada, sino a Briseida; y ya el mejor caracterizador de la literatura griega, Homero, había proporcionado un modelo para ello a Severo, hecho éste al que Karnthaler no parece haber prestado la debida importancia en su comentario. En Il. I 348, Homero describe con una sola palabra la actitud de Briseida que marcha de mala gana con los heraldos (? ????s'). Además, Briseida interviene en Homero una sola vez, en Il. XIX 287-300, haciendo un sentido lamento ante el cadáver de Patroclo, por quien sentía espe- 
cial afecto, debido a que él le hizo concebir esperanzas sobre su boda con Aquiles y le impidió hundirse en el desánimo en momentos difíciles para ella. En esa dolida intervención (en la que precisamente Briseida menciona el momento en que fue llevada por los heraldos), al recordar sus desgracias y desventuras anteriores (destrucción de su patria, muerte de sus hermanos y es-

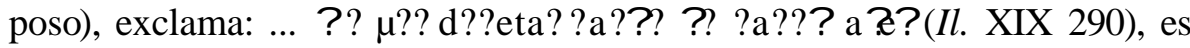
decir, «desgracia sobre desgracia me viene sin cesar». Parece claro que Severo ha construido su ejercicio a partir de esa idea y teniendo en mente esta intervención de Briseida. Además, un término clave en la composición es

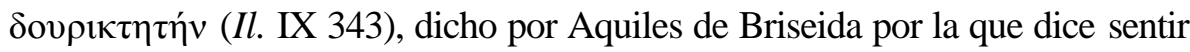
gran amor. Severo emplea sinónimos de este término homérico más comprensibles (a??p???t?? y d?????t??), en la línea de las glosas presentes en los léxicos utilizados en las escuelas bizantinas. Y lo mismo puede decirse de las expresiones con las que Briseida se refiere a la destrucción de su patria y

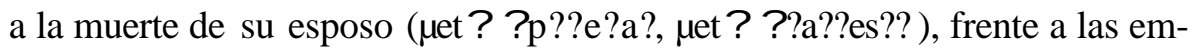
pleadas por Homero (??te??e?, p??se?, deda?? $\mu$ ????). Severo emplea una sintaxis fácil y términos comprensibles para los lectores de su época, términos que están presentes en historiadores (Herodoto, Tucídides, Jenofonte y Polibio), en oradores (Andócides e Iseo) y en los textos bíblicos (Nuevo Testamento y Los Setenta). Por otro lado, y aunque no necesariamente dependan de su modelo, las repeticiones puestas en boca de Briseida como fruto de la emoción encuentran un precedente en el ??d? $\mu$ ?? ??d? $\mu$ ' ?as?e? con el que se dirige a Patroclo (Il. XIX 295). En cuanto al paréntesis, hay que decir que su contenido es necesario y propio de la etopeya. Como veremos, según Eustacio de Tesalónica, la suposición es una de las características de la etopeya. En ella el personaje puede conjeturar sobre su futuro, pero no debe dar la impresión de saberlo, pues no sería coherente, salvo que se tratase de una profetisa o lo supiese de boca de un dios. Por lo demás, según el rétor Hermógenes, atenuar una afirmación es un rasgo de "equidad", que confiere ???? al discurso.

\section{Consideraciones finales.}

Con este repaso hemos pretendido ofrecer una visión panorámica de la etopeya de temática del ciclo troyano. Para ello hemos intentado compaginar los datos de la preceptiva retórica sobre el ejercicio, sus ejemplos prácticos y 
la importancia del modelo homérico. La relación e influencia mutua no presenta una sola dirección desde la escueta preceptiva del ejercicio transmitida en época imperial hasta los ejemplos prácticos, pues aunque sin duda en las composiciones ha influido la preceptiva con sus modelos propuestos, no es menos cierto que, ya desde los orígenes de la etopeya hasta época bizantina tardía, el modelo homérico y sus interpretaciones retóricas de algún modo han determinado, en un proceso a la vez sincrónico y diacrónico, la evolución teórica de la etopeya y la naturaleza de las composiciones prácticas, tanto en el tema como en la forma ${ }^{41}$.

Por lo demás, a fin de ilustrar mejor los diversos aspectos teóricos tratados en el trabajo, nos ha parecido oportuno incluir, a modo de ejemplo, un abundante número de pasajes, los cuales no habrán de ser, seguramente, lo menos valioso de nuestro estudio. Hemos elaborado una recopilación y organización de las etopeyas conservadas según criterios temáticos; en tal catálogo, tras los datos de cada etopeya, hemos añadido las referencias de sus fuentes y paralelos, muchos de los cuales habían pasado inadvertidos a editores y estudiosos. Asimismo, hemos organizado los datos de Eustacio de Tesalónica sobre la presencia de la etopeya en Homero siguiendo criterios puramente retórico-escolares, intentado también en este punto que el aporte de material fuera lo más exhaustivo posible. Hemos llevado a cabo, en fin, un estudio sobre la forma y el contenido de las etopeyas, gracias al cual han quedado desveladas - creemos - las preferencias temáticas de sus autores, así como algunas características de su técnica compositiva.

41 En Occidente la temática retórica fue extraída principalmente de Virgilio (cf. Seruius, Aen. X 18; véase Th. Haarhof, Schools of Gaul: A Study of Pagan and Christian Education in the Last Century of the Western Empire, Oxford, 1920, pp. 69-71). Nosotros creemos que tal vez llegaríamos a conclusiones parecidas a las de nuestro trabajo, si abordásemos el estudio de la etopeya en lengua latina a través de los textos de Virgilio, los comentarios de la Eneida realizados por Servio y otros autores, las etopeyas de temática virgiliana conservadas (entre otras, las parafrásticas incluidas en Riese, Anthologia Latina siue Poesis Latinae supplementum, vol. 1 , p. 187 y ss.) y la preceptiva sobre la etopeya transmitida por los rétores latinos. 